\title{
Management of traumatic events: influence of emotion-centered coping strategies on the occurrence of dissociation and post-traumatic stress disorder
}

\author{
This article was published in the following Dove Press journal: \\ Neuropsychiatric Disease and Treatment \\ 16 March 2011 \\ Number of times this article has been viewed
}

\author{
Georges Brousse ${ }^{1,2}$ \\ Benjamin Arnaud' \\ Jordane Durand Roger' \\ Julie Geneste' \\ Delphine Bourguet' \\ Frederic Zaplana' \\ Olivier Blanc' \\ Jeannot Schmidt ${ }^{1,2}$ \\ Louis Jehel ${ }^{3}$ \\ 'CHU Clermont Ferrand, Unité \\ Urgences Psychiatriques, \\ 28 place Henri Dunant BP 69, 63003 \\ Clermont-Ferrand Cedex 0I, France \\ ${ }^{2}$ Univ Clermont I, UFR Médecine, \\ Clermont-Ferrand, F6300I France \\ ${ }^{3}$ Hopital Tenon (CHU APHP) 4 rue de \\ la Chine 75020, France, INSERM U669
}

Correspondence: Georges Brousse $\mathrm{CHU}$ Clermont Ferrand, Unité Urgences Psychiatriques, 28 Place Henri Dunant BP 69, 63003 Clermont-Ferrand Cedex 0I, France

Tel +330473754780

Fax +330473754 78I

Email gbrousse@chu-clermontferrand.fr

\begin{abstract}
Our aim was to assess the influence of the coping strategies employed for the management of traumatic events on the occurrence of dissociation and traumatic disorders. We carried out a 1-year retrospective study of the cognitive management of a traumatic event in 18 subjects involved in the same road vehicle accident. The diagnosis of post-traumatic stress disorder (PTSD) was made for $33.3 \%$ of the participants. The participants with a PTSD diagnosis 1 year after the event used emotion-centered strategies during the event more often than did those with no PTSD, $P<0.02$. In the year after the traumatic event, our results show a strong link between the intensity of PTSD and the severity of the post-traumatic symptoms like dissociation $(P=0.032)$ and the use of emotion-centered strategies $(P=0.004)$. Moreover, the participants who presented Peritraumatic Dissociative Experiences Questionnaire scores above 15 made greater use of emotion-centered coping strategies than did those who did not show dissociation, $P<0.04$. Our results confirm that the cognitive management of traumatic events may play an essential role in the development of a state of post-traumatic stress in the aftermath of a violent event.
\end{abstract}

Keywords: trauma, coping, emotions, peritraumatic dissociation, post-traumatic stress disorder

\section{Introduction}

Post-traumatic stress disorder (PTSD) is a particularly disabling illness induced by exposure to a shocking event. ${ }^{1,2}$ The prevalence of this disorder is high, with figures for the general population in the range of $1 \%-9 \%$ and up to $39 \%$ among victims of road accidents..$^{3-5}$

Although the onset of PTSD after experiencing a traumatic event is still hard to predict, the presence of a state of peritraumatic dissociation (time distortion, reduced awareness, emotional numbing, amnesia, and derealization) may influence its advent nonspecifically. ${ }^{6-10}$ However, this reaction, which reflects the immediate impact of the event, is complex and heterogeneous, and it has been suggested that its clinical dimensions or factors associated with its onset should be examined. ${ }^{8}$ Hence, the study of the immediate response to the traumatic experience offers a promising avenue of investigation, in particular through the coping strategies used by patients to mitigate or control external threats. ${ }^{11}$

For Folkman and Lazarus, ${ }^{12}$ coping corresponds to all the cognitive and behavioral efforts made to control, reduce, or tolerate the internal or external requirements that threaten or overwhelm the individual's response capacity, ie, the regulation of emotional 
distress (internal) and problem management (internal or external). Several authors have sought to characterize these strategies, eg, according to how the subject reacts to the situation. ${ }^{13-15}$ In this article, we refer to three types of regulations proposed by Lazarus and Folkman ${ }^{16}$ in 1984. These regulations are problem-centered coping, emotion-centered coping, and coping centered on social support. Problemcentered coping comprises two factors: problem solving (seeking information, devising action plans) and facing the situation (direct effort and action to address the problem). Emotion-centered coping is an attempt to manage the emotional responses induced by the situation. This management or regulation of the emotions can be performed in different ways (emotional, physiological, cognitive, or behavioral). Numerous strategies belong to this category, including substance use, physical activity, expression of emotions, feeling of responsibility, minimization of the event, alteration, denial or avoidance of reality, hoping for a miracle, and use of the imagination. Among all these emotional behaviors, avoidance of the event seems to particularly influence evolution to PTSD, suggesting that emotion-centered strategies (avoidance, flight, denial, or self-accusation) may lead to more negative outcomes after a traumatic event than do problemcentered strategies (seeking information, making problemsolving plans). ${ }^{17-19}$ Emotion regulation deficits may also be associated with negative outcome to PTSD. ${ }^{20}$ However, the place taken by emotion-centered strategies other than avoidance has not been fully explored. We set out to examine the influence of emotional response in the occurrence of disorders, both acute (peritraumatic dissociation) and delayed (PTSD) after exposure to a traumatic event.

The main aim of our study was to seek a link between the use of emotion-centered strategies and the occurrence of a state of post-traumatic stress. Our secondary aims were to assess the link between peritraumatic dissociation and PTSD and to show that the implementation of emotion-centered coping strategies was more often associated with the intensity of peritraumatic dissociation.

\section{Method}

This was a retrospective study of a population of 24 firefighters who survived a bus crash in May 2005. This particularly serious accident, involving 26 people (two dead, four seriously injured), occurred while they were travelling abroad on a trip. This noninvasive research was approved by an ethical institutional board.

Data collection was carried out 1 year after the traumatic event using a standardized semistructured questionnaire to record sociodemographic data associated with clinical evaluation scales comprising the following:

- The Mini-International Neuropsychiatric Interview (MINI) and the Clinician-administered PTSD Scale Part 2 (CAPS-2), which determines the diagnosis of PTSD according to the Diagnostic and Statistical Manual of Mental Disorders, 4th Edition, and measures its intensity. ${ }^{21-23}$

- The Peritraumatic Dissociative Experiences Questionnaire (PDEQ), a 10-item self-questionnaire used for the retrospective assessment of awareness dissociation features on exposure to trauma. ${ }^{24}$ The French version (PDEQ-10- Self Report Version [SRV]) used was translated by Birmes et al. ${ }^{25}$ The score was obtained by summing the 10 items. Marmar et $\mathrm{al}^{26}$ suggested a clinical positive threshold of 15 (score above which patients are considered as having presented an episode of peritraumatic dissociation).

- The Ways of Coping Checklist (WCC), a coping scale inspired by Folkman and Lazarus' transactional model of stress. ${ }^{27}$ The original scale had 68 items and assigned coping strategies to three types: problem-centered, emotion-centered, and centered on social support, defined by Lazarus and Folkman. ${ }^{16}$ In our study, we used the 42-item French version validated by BruchonSchweitzer et al. ${ }^{28}$ This French version presents a strong construct and criterion validity, and the factor structure is stable across gender.

The participants who gave informed consent were seen individually at a visit in the psychiatry unit of the emergency ward. The interviews, which lasted 3 hours, were carried out by the same psychiatrist, who was trained in administering questionnaires. All the patients were evaluated during the month of May 2006, ie, 1 year after the accident. The assessment of PTSD occurrence using CAPS-2 and MINI was carried out over the previous 11 months (so that PTSDs resolving in this period were included). Self-questionnaires were also administered during this visit. With regard to the instructions, the stated reference period for filling out the PDEQ and WCC self-questionnaires was the period immediately following the event.

\section{Statistical analysis}

We used version 15.0 of the SPSS software (SPSS Inc., Chicago, IL, USA) to conduct statistical analyses. Sociodemographic data and scale scores were processed with the descriptive statistics method. The normality of the data was assessed by calculating skewness and kurtosis 
statistics (the criterion chosen was that the dividend of the coefficient and the standard errors did not exceed \pm 2.0 ). All score scales were normally distributed. Relationships between continuous variables were analyzed with Pearson's product moment correlation coefficient. The following procedure was employed to identify bivariate outliers. First, scale scores were transformed in $Z$ scores (ie, mean $[\mathrm{M}]=0$ and standard deviation $[\mathrm{SD}]=1$ ), then Mahalanobis $D^{2}$ was measured. ${ }^{29} Z$ and $D^{2}$ critical thresholds were 2.70 and 9.92, respectively. No participant exceeded the thresholds. Because of the small size of the sample, between-group comparisons were performed with a two-tailed nonparametric test (Mann-Whitney $U$ test), and a $\chi^{2}$ statistic was used to compare nominal variables. A probability value of 0.05 was taken as the significance level. In order to explore the influence of dissociation on the occurrence of PTSD we chose to dichotomize the sample in two groups based on the approach proposed by Marmar et al, ${ }^{26}$ who suggested that patients who presented a clinical positive threshold of 15 on the PDEQ are considered as having an episode of peritraumatic dissociation.

\section{Results}

Out of the 24 people involved in the accident, 18 (75\%, 11 men and 7 women) agreed to take part in our study (mean age: 46.6 years \pm 11.1 , Table 1). Six patients could not be included in the study, of whom two had moved, two had neurological sequelae that were not compatible with filling out questionnaires, and two refused to recall the accident. No difference between participants and nonparticipants concerning mean age and gender was found (Table 1). All participants had similar educational level (associate-level degree).

PTSD was diagnosed 1 year after the event for six participants (33.3\%) by the MINI and confirmed by the CAPS-2 (Table 2). All the patients received psychotherapeutic care after the event. One year after the event, eight patients $(44.4 \%)$ were taking anxiolytic drugs, one-third antidepressants, and one-third hypnotics. Of the symptoms most often reported 1 year after the event, 13 participants (72.2\%) experienced flashbacks and seven (38.9\%) experienced arousal. Distress was clinically significant in eight participants (44.4\%, Table 2$)$.

Assessment of peritraumatic dissociation gave a mean PDEQ score of 21.5 ( $\mathrm{SD}=9.8)$. A clinical score above the threshold of 15 was presented by 12 participants $(66.7 \%)$.

For the immediate information, the mean WCC scores were $24.6(\mathrm{SD}=5.2)$ for problem-centered strategies, $21.1(\mathrm{SD}=7.6)$ for emotion-centered strategies, and 24.7 $(\mathrm{SD}=4.3)$ for strategies centered on social support.

\section{Peritraumatic dissociation and PTSD}

The total CAPS-2 score (mean $[\mathrm{M}]=33.3, \mathrm{SD}=26.8$ ) was significantly correlated with that of the PDEQ ( $\mathrm{M}=21.5$, $\mathrm{SD}=9.8), r=0.521, P<0.05$ (Table 3). Of the participants presenting with a PTSD 1 year after the event, those who presented a peritraumatic dissociation after the trauma differed from those who did not (PDEQ score $<15$ ) in their CAPS-2 total score $(\mathrm{M}=40.1 \pm 25.4$ vs $\mathrm{M}=9.8 \pm 10.5), Z=2.536$, $P<0.01$, and their mean scores for two criteria of CAPS-2 (Table 2). However, of the participants who presented no PTSD 1 year after the event, 50\% gave a PDEQ scale score above the threshold score of 15 .

\section{PTSD and coping strategies}

The participants who presented a PTSD 1 year after the event used emotion-centered strategies more often $(\mathrm{M}=28.5, \mathrm{SD}=2.4)$ than did those with no PTSD $(\mathrm{M}=18.9, \mathrm{SD}=7.3), Z=-2.341, P<0.02$, and, in particular, self-accusation $(\mathrm{M}=10.0, \mathrm{SD}=1.8$ and $\mathrm{M}=5.2$, $\mathrm{SD}=2.2$, respectively), $Z=-2.652, P<0.01$ (Table 4). The mean score for the use of the emotion-centered strategies of the WCC was correlated with the total

Table I Descriptive and comparative statistics concerning participants and nonparticipants

\begin{tabular}{lllc}
\hline Total population $(\mathbf{N}=\mathbf{2 4})$ & Number of participants $(\mathbf{N}=18)$ & Number of nonparticipants $(\mathbf{N}=\mathbf{6})$ & $\chi^{\mathbf{2}}$ \\
\hline Gender & & & $P$ \\
$\quad$ Males (\%) & II (6I.I) & $4(66.7)$ & 0.018 \\
Females (\%) & $7(38.9)$ & $2(33.3)$ & $>0.05$ \\
& & & $>0.03$ \\
Mean age, years (standard deviation) & $46.6(11.1)$ & $40.7(3.6)$ & $\mathbf{Z}$ \\
Treatment at I year after event & & & -1.002 \\
$\quad$ Antidepressant (\%) & $6(33.3)$ & $\mathrm{NC}$ & 0.317 \\
Anxiolytic (\%) & $8(44.4)$ & $\mathrm{NC}$ & $\mathrm{NC}$ \\
Hypnotic (\%) & $6(33.3)$ & & \\
\hline
\end{tabular}

Abbreviation: NC, not communicated. 
Table 2 Relation between peritraumatic dissociation, coping strategies, and post-traumatic stress disorder

\begin{tabular}{|c|c|c|c|c|c|c|c|c|c|c|c|c|}
\hline & \multicolumn{3}{|c|}{$\begin{array}{l}\text { Total population } \\
(\mathbf{N}=18)\end{array}$} & \multirow{2}{*}{$\begin{array}{l}\text { Participants above } \\
\text { the threshold } \\
(\mathrm{N}=18) \\
\mathrm{N}(\%)\end{array}$} & \multicolumn{3}{|c|}{$\begin{array}{l}\text { Peritraumatic } \\
\text { dissociation present } \\
(\text { PDEQ } \geq 15, N=12 \text { ) }\end{array}$} & \multicolumn{3}{|c|}{$\begin{array}{l}\text { Peritraumatic } \\
\text { dissociation absent } \\
(\text { PDEQ }<15, N=6)\end{array}$} & \multirow[t]{2}{*}{$\mathbf{Z}$} & \multirow[t]{2}{*}{$P$} \\
\hline & Mean & SD & Range & & Mean & SD & $\overline{\text { Range }}$ & Mean & SD & $\overline{\text { Range }}$ & & \\
\hline \multicolumn{13}{|l|}{ Criteria of CAPS-2 } \\
\hline $\begin{array}{l}\text { A: Presence of } \\
\text { traumatic event }\end{array}$ & & & & $18(100)$ & & & & & & & & \\
\hline B: Flashback & 13.0 & 11.1 & $0-33$ & $13(72.2)$ & 17.1 & 10.6 & $1-33$ & 2.8 & 5.7 & $0-13$ & 2.647 & 0.008 \\
\hline C: Avoidance/numbing & 10.0 & 9.9 & $0-29$ & $6(33.3)$ & 10.0 & 8.9 & $0-29$ & 5.0 & 4.6 & $0-9$ & 1.010 & 0.312 \\
\hline D: Arousal & 10.3 & 9.4 & $0-30$ & 7 (38.9) & 13.0 & 9.3 & $0-30$ & 2.0 & 2.4 & $0-6$ & 2.438 & 0.015 \\
\hline E: Duration & 9.2 & 4.9 & $0-12$ & $15(83.3)$ & & & & & & & & \\
\hline \multicolumn{13}{|l|}{$\geq 3$ months } \\
\hline F: Distress & 3.4 & 3.2 & $0-9$ & $8(44.4)$ & 4.2 & 3.4 & $0-9$ & 1.0 & 1.2 & $0-3$ & $\mathrm{I} .724$ & 0.085 \\
\hline Total CAPS-2 score & 33.3 & 26.8 & $2-80$ & $6(33.3)^{\mathrm{a}}$ & 40.1 & 25.4 & $8-80$ & 9.8 & 10.5 & $2-28$ & 2.536 & 0.011 \\
\hline \multicolumn{13}{|l|}{ WCC strategies } \\
\hline Problem solving & 24.6 & 5.2 & $17-35$ & & 25.4 & 5.5 & $17-35$ & 21.2 & 2.6 & $17-24$ & 1.273 & 0.203 \\
\hline $\begin{array}{l}\text { Emotion-centered } \\
\text { coping }\end{array}$ & 21.1 & 7.6 & $9-34$ & & 22.9 & 7.3 & $10-34$ & 14.8 & 4.7 & $9-22$ & 2.059 & 0.039 \\
\hline Social support & 24.7 & 4.3 & $17-32$ & & 24.9 & 4.4 & $17-32$ & 23.6 & 4.5 & $18-29$ & 0.597 & 0.597 \\
\hline PDEQ & 21.5 & 9.8 & $|0-4|$ & $12(66.7)$ & & & & & & & & \\
\hline
\end{tabular}

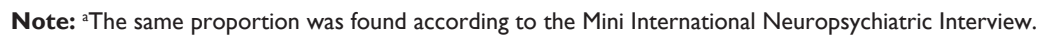

Abbreviations: CAPS-2, Clinician-administered PTSD Scale Part 2; PDEQ, Peritraumatic Dissociative Experiences Questionnaire; SD, standard deviation; WCC, Ways of Coping Checklist.

CAPS-2 score, $r=0.642, P=0.004$ (Table 3). Significant correlation coefficients were obtained for self-accusation and imagination strategies (Table 3).

\section{Peritraumatic dissociation and coping strategies}

The subjects who presented a PDEQ score above 15 used emotion-centered coping strategies more often $(\mathrm{M}=22.9$, $\mathrm{SD}=7.3)$ than did the others $(\mathrm{M}=14.8, \mathrm{SD}=4.7), Z=2.059$, $P<0.04$ (Table 2). Moreover, we found no significant link between coping strategies as classified into three types by the WCC (ie, problem-centered, emotion-centered, and centered on social support) and the intensity of the peritraumatic dissociation measured by the PDEQ. On the other hand, using the classification of Roth and Cohen ${ }^{13}$ (approach versus avoidance), we obtained a significant positive correlation between the intensity of the peritraumatic dissociation (PDEQ score) and the implementation of avoidant coping strategies (measured on the WCC scale), $r=0.506, P<0.04$, but not for the other emotion-centered strategies (self-accusation or imagination (Table 3).

\section{Discussion}

Our results show a strong link between the intensity of PTSD and the severity of the post-traumatic symptoms like dissociation and the use of emotion-centered strategies. They support the hypothesis that there is a link between the intensity of peritraumatic dissociation after the event and the intensity of PTSD, as shown by the correlation between the CAPS-2 and PDEQ scores. These results are consistent with those in the literature ${ }^{30-32}$ and, in particular, for road accident victims, as shown by a study by Ursano et al, ${ }^{33}$

Table 3 Correlation coefficients (Pearson's $r$ ) between Clinician-administered PTSD Scale Part 2 (CAPS-2) and Peritraumatic Dissociative Experiences Questionnaire (PDEQ) scores and coping strategies measured by the Ways of Coping Checklist

\begin{tabular}{lllllll}
\hline $\mathbf{N}=18$ & $\mathbf{C A P S}-2$ & PDEQ & Emotion & Avoidance & Imagination & Self-accusation \\
\hline PDEQ & $0.521^{\mathrm{a}}$ & & & & & \\
Emotion & $0.642^{\mathrm{b}}$ & 0.417 & & & & \\
Avoidance & 0.326 & $0.506^{\mathrm{a}}$ & $0.617^{\mathrm{b}}$ & & & \\
Imagination & $0.529^{\mathrm{a}}$ & 0.285 & $0.878^{\mathrm{c}}$ & $0.654^{\mathrm{b}}$ & $0.782^{\mathrm{c}}$ & 0.336 \\
Self-accusation & $0.664^{\mathrm{b}}$ & 0.199 & $0.901^{\mathrm{c}}$ & 0.393 & 0.459 & 0.463 \\
Problem solving & 0.021 & -0.034 & 0.266 & 0.182 & 0.335 & \\
Social support & 0.208 & 0.109 & 0.379 & 0.052 & & \\
\hline
\end{tabular}

Notes: ${ }^{\mathrm{P}} \mathrm{P}<0.05$; ${ }^{\mathrm{b}} \mathrm{P}<0.01$; ${ }^{\mathrm{c} P}<0.001$. 
Table 4 Comparison of mean Ways of Coping Checklist (WCC) scores between participants with and without post-traumatic stress disorder (PTSD)

\begin{tabular}{|c|c|c|c|c|c|c|c|c|}
\hline \multirow[t]{2}{*}{ WCC strategies } & \multicolumn{3}{|c|}{ PTSD present $(\mathbf{N}=6)$} & \multicolumn{3}{|c|}{ PTSD absent $(\mathrm{N}=12)$} & \multirow[t]{2}{*}{$\mathbf{Z}$} & \multirow[t]{2}{*}{$P$} \\
\hline & Mean & Standard deviation & Range & Mean & Standard deviation & Range & & \\
\hline Problem solving & 25.5 & 5.3 & $20-31$ & 24.3 & 5.4 & $17-35$ & -0.267 & 0.789 \\
\hline Emotion-centered strategies & 28.5 & 2.4 & $25-30$ & 18.9 & 7.3 & $9-34$ & -2.341 & 0.019 \\
\hline Avoidance & 14.5 & 3.3 & $10-18$ & 12.8 & 3.8 & $7-22$ & -0.962 & 0.336 \\
\hline Self-accusation & 10.0 & 1.8 & $8-12$ & 5.2 & 2.2 & $3-9$ & -2.652 & 0.008 \\
\hline Imagination & 21.0 & 3.2 & $18-25$ & 16.4 & 4.7 & $9-24$ & -1.703 & 0.089 \\
\hline Social support & 27.5 & 3.7 & $23-32$ & 23.9 & 4.2 & $17-29$ & -1.280 & 0.201 \\
\hline
\end{tabular}

who found that road accident victims with peritraumatic dissociation were 4.12 times more likely to develop an acute PTSD and 4.8 times more likely to develop a chronic PTSD than the other patients. This link between the intensity of the dissociational state and the onset of a PTSD has been challenged in a literature review, especially when the assessment is retrospective. ${ }^{34}$ However, although the patients who developed a PTSD presented symptoms of peritraumatic dissociation after the event, the presence of this dissociation did not necessarily imply the subsequent onset of a PTSD, as all the patients presented symptoms of peritraumatic dissociation after the accident (lowest score 10). In fact, this symptomatic picture, which is sensitive but not specific, is still poorly predictive of evolution toward a PTSD (unless very intense) and highlights the need to continue research on predictivity factors. ${ }^{8}$ Improved predictivity might, for example, be obtained by using the clinical detection threshold of the PDEQ (score $\geq 15$ ) proposed by Marmar et al. ${ }^{26}$ In our sample, all the patients with PTSD and $50 \%$ of the patients without PTSD 1 year after the event presented clinical peritraumatic dissociation (score $\geq 15$ ) after exposure, suggesting that a higher clinical threshold (score $\geq 22$ ) might be preferable, as advocated by Birmes et al. ${ }^{35}$ In our sample, only three patients had a score greater than 22 , so we did not test this threshold.

The study of coping strategies implemented to deal with an event may help to define predictability criteria. In our study, the patients presenting a state of post-traumatic stress differed in the coping strategies they implemented after the event from those without this disorder. The participants who presented a PTSD used emotion-centered strategies more often than did those with no PTSD. This relationship may appear in the early reactions, because there seems to be a relationship between the onset of acute disorder and the use of emotion-centered coping strategies. Thus, there was a link between the onset of a state of peritraumatic dissociation and the use of emotion-centered coping strategies.
To our knowledge, the literature reports no work linking emotion-centered strategies to PTSD, apart from the link between the use of avoidant coping strategies and the onset of peritraumatic dissociation. ${ }^{18,19}$ Avoidance strategies are disturbance associated with sustainability of traumatism, as shown in a study by Golier et al, ${ }^{17}$ in which the authors show in a population of Holocaust survivors that the subjects presenting with a PTSD had recourse to avoidance strategies when faced with trauma exposure. Our work underlines this influence. However, in our work, to extend the literature, we considered not only avoidance strategies but also other types of emotion-centered strategies (self-accusation and recourse to the imagination). This choice stems from the specific context of the study in which a group of victims suffered a traumatic event (a road traffic accident) that occurred at night in a foreign country. In most cases, the victims would not have had time to develop a problem-centered strategy at the moment of the event, because of the suddenness and unexpectedness of this type of accident. In our samples, we can suppose that most victims did not have the opportunity to resolve the problem by developing coping strategies focusing on problem resolution or social support. Indeed, they were in a foreign country and did not speak the language of their rescuers whom they had to wait for 2 hours. Those who have successfully used these strategies have been protected from an unfavourable evolution to dissociation and PTSD. In other types of traumatic event (eg, repeated trauma), it is possible to envisage problem-centered cognitive strategies or nonacute emotional regulation strategies (eg, substance use). This finding raises the question of the influence of the type of event on the type of cognitive strategy developed by individuals. Chung et $\mathrm{al}^{36}$ have shown that the type of traumatic event (82 witnesses of aircraft accidents versus 66 witnesses of train accidents) influences the type of coping strategy implemented (studied using the WCC). This relationship underlines the need to homogenize the population studied as regards the traumatic event to avoid bias specific to this factor. Our study 
also highlights the importance of setting in place immediate therapeutic action based on social and emotional support to address risk-associated cognitive responses. The patients described here did not benefit from this assistance, as their accident happened at night in an isolated spot in a foreign country. Finally, it is also important to note that the use of emotion-focused strategies is not always maladaptive, and it may be more beneficial that this strategy helps overcome the trauma. The help of an empathic therapist in the immediate aftermath of the confrontation or years later may favor resolution. ${ }^{37}$

This work admittedly suffers from a number of limitations, starting with the small sample size, which was justified by our wish to examine a population confronted homogeneously with the same event and to study the coping strategies it implemented. In addition, the retrospective assessment of the processing of the trauma information may be criticized, as the retrospectively measured coping strategy can be modified by the current state and by psychotropic treatment. However, an earlier measurement could equally have been modified by the peritraumatic reaction. ${ }^{38}$ Also, several authors consider that coping measured by WCC is stable in time. ${ }^{28,36}$ Concerning the PDEQ, Wittmann et $\mathrm{al}^{39}$ consider that its retrospective assessment is questionable, whereas Marmar et $\mathrm{al}^{40}$ report a very high stability in time for this scale. Thus, further work needs to be done to explore the importance of immediate processing of information in subsequent outcome. The last limit of our study is that we present "group" differences and analyses with a bisecting of a continuous variable (PDEQ), and this choice can have adverse consequences on the analysis. Other studies have been undertaken in order to check whether the threshold of 15 proposed by Marmar et $\mathrm{al}^{26}$ can be valid to define categorical data.

\section{Conclusion}

The cognitive management of traumatic events has to date been under-researched, and yet it may play an essential role in the development of a state of post-traumatic stress in the aftermath of a shocking event, as shown in this study. It is a factor of influence to be combined with others that have already been identified, such as the type of event and individual perception of it. ${ }^{2,31}$ In our study, the first variable was controlled, as the event was the same for all the subjects. In addition, we found that the cognitive management of the trauma was linked to peritraumatic dissociation, which, in the literature, is strongly predictive of the subsequent onset of a PTSD. ${ }^{33,36,41}$ In particular, coping strategies focused on emotions seem particularly involved in the occurrence of disturbances. It is not clear whether this relates to the use of these strategies or failure of these strategies during their use. If the characteristics of a profile that is especially vulnerable to a PTSD can be identified after a traumatic event, then victims can be offered early care adapted to their coping style.

\section{Acknowledgement}

We thank the Trauma Psy Association and its Chair, MarieChristine Millequand, for support.

\section{Disclosure}

The authors report no conflicts of interest in this work.

\section{References}

1. Crocq L, Doutheau C, Louville P, Cremniter D. Psychiatrie de catastrophe. Réactions immédiates et différées, troubles séquellaires. Paniques et psychopathologie collective. Enc Med Chir. 1998;37-113-D-10:8.

2. Jolly A. Evénements traumatiques et état de stress post-traumatique. Une revue de la littérature épidemiologique. Ann Med Psyc. 2000;158: 370-378.

3. Alonso J, Angermeyer MC, Bernert S, et al. Prevalence of mental disorders in Europe: results from the European Study of the Epidemiology of Mental Disorder (ESEMeD) project. Acta Psychiatr Scand. 2004;420(Supp1):S21-S27.

4. Bellamy V, Roelandt J, Caria A. Troubles mentaux et représentation de la santé mentale: premiers résultats de l'enquête Santé mentale en population générale. Etudes et résultats. Direction de la recherche, des études de l'évaluation et des statistiques (France); 2004.

5. Blanchard EB, Hickling EJ, Taylor AE, et al. Who develops PTSD from motor vehicle accidents? Behav Res Ther. 1996;34:1-10.

6. Birmes P, Brunet A, Carreras D, et al. The predictive power of peritraumatic dissociation and acute stress symptoms for posttraumatic stress symptoms: a three-month prospective study. Am J Psychiatry. 2003;160: 1337-1339.

7. Bryant RA. Predicting posttraumatic stress disorder from acute reactions. J Trauma Dissociation. 2005;6:5-15.

8. Bryant RA. Does dissociation further our understanding of PTSD? J Anxiety Disord. 2007;21:183-191.

9. Marmar CR, Weiss DS, Metzel TJ, et al. Longitudinal course and predictors of continuing distress following critical incident exposure in emergency services personnel. J Nerv Ment Dis. 1999;187:15-22.

10. Murray J, Ehlers A, Mayou RA. Dissociation and posttraumatic stress disorder: two prospective studies of road traffic accident survivors. $B r J$ Psychiatry. 2002;180:363-368.

11. Allen JG. Coping With Trauma: Hope Through Understanding. 2nd ed. Washington DC: American Psychiatric Publishing, Inc; 2005.

12. Folkman S, Lazarus RS. The relationship between coping and emotion: implications for theory and research. Soc Sci Med. 1998;26:309-317.

13. Roth S, Cohen LJ. Approach, avoidance, and coping with stress. Am Psychol. 1986;41:813-819.

14. Steptoe A. Invited review. The links between stress and illness. J Psychosom Res. 1991;35:633-644.

15. Suls J, Fletcher B. The relative efficacy of avoidant and nonavoidant coping strategies: a meta-analysis. Health Psychol. 1985;4:249-288.

16. Lazarus RS, Folkman S. Stress, Appraisal and Coping. New York: Springer; 1984.

17. Golier JA, Yehuda R, Lupien SJ, Harvey P. Memory for trauma-related information in Holocaust survivors with PTSD. Psychiatry Res. 2003; 121:133-143.

18. Olff M, Langeland W, Gersons B. The psychobiology of PTSD: coping with trauma. Psychoneuroendocrinology. 2005;30:974-982. 
19. Marmar CR, Weiss DS, Metzler TJ. The relationship of peritraumatic dissociation and posttraumatic stress: findings in female Vietnam theatre veterans. J Consult Clin Psychol. 1996;64:1054-1059.

20. Price J, Monson C, Callahan K, Rodriguez B. The role of emotional functioning in military-related PTSD and its treatment. JAnxiety Disord. 2006;20:661-674.

21. Sheehan DV, Lecrubier Y, Sheehan HK, et al. The Mini International Neuropsychiatric Interview (M.I.N.I.): the development and validation of a structured diagnostic psychiatric interview. Clin Psychiatry. 1998; 59:22-33.

22. Lecrubier Y, Sheehan DV, Weiller E, et al. The Mini International Neuropsychiatric Interview (MINI). A short diagnostic structured interview: reliability and validity according to the CIDI. Eur Psychiatry. 1997;12:224-231.

23. Blake DD, Weathers FW, Nagy LM, et al. The development of a clinician-administered PTSD scale. J Trauma Stress. 1995;8:75-90.

24. Marmar CR, Weiss DS, Metzler TJ. The Peritraumatic Dissociative Experiences Questionnaire. Assessing Psychological Trauma and PTSD. Wilson JP, Keane TM, editors. New York: The Guilford Press; 1997:412-428.

25. Birmes P, Brunet A, Benoit M, et al. Validation of the Peritraumatic Dissociative Experiences Questionnaire self-report version in two samples of French-speaking individuals exposed to trauma. Eur Psychiatry. 2005;20:145-151.

26. Marmar CR, Weiss DS, Metzler TJ, Delucchi K. Characteristics of emergency services personnel related to peritraumatic dissociation during critical incident exposure. Am J Psychiatry. 1996;153:94-102.

27. Folkman S, Lazarus RS. Folkman-Lazarus Ways of Coping Checklist. Princeton University Press: Educational Testing Service; 1983.

28. Bruchon-Schweitzer M, Cousson F, Quintard B, et al. French adaptation of the Ways of Coping Checklist. Percept Mot Skills. 1996;83: 104-106.

29. Mahalanobis PC. On the generalised distance in statistics. Proc Natl Inst Sci India. 1936;2:49-55.

30. Fullerton CS, Ursano RJ, Epstein RS, et al. Peritraumatic dissociation following motor vehicle accidents: relationship to prior trauma and prior major depression. J Nerv Ment Dis. 2000;188:267-272.
31. Jehel L, Paterniti S, Brunet A, et al. Peritraumatic distress prospectively predicts PTSD symptoms in assault victims. Encephale. 2006;32: 953-956.

32. Ozer EJ, Best SR, Lipsey TL, Weiss DS. Predictors of posttraumatic stress disorder and symptoms in adults: a meta-analysis. Psychol Bull. 2003;129:52-73.

33. Ursano RJ, Fullerton CS, Eptein RS, et al. Peritraumatic dissociation and postraumatic stress disorder following motor vehicle accidents. Am J Psychiatry. 1999;156:1808-1810.

34. Candel I, Merckelbach H. Peritraumatic dissociation as a predictor of posttraumatic stress disorder: a critical review. Compr Psychiatry. 2004; 45:44-50.

35. Birmes P, Carreras D, Charlet JP, et al. Peritraumatic dissociation and posttraumatic stress disorder in victims of violent assault. J Nerv Ment Dis. 2001;189:796-798.

36. Chung MC, Dennis I, Eastophe Y, et al. A multiple indicator multiple cause model for posttraumatic stress reactions: personality, coping, and maladjustment. Psychosom Med. 2005;67:251-259.

37. Paivio SC, Laurent CJ. Empathy and emotion regulation: reprocessing memories of childhood abuse. Clin Psychol. 2001;57(2):213-226.

38. Jehel L, Brunet A, Paterniti S, Guelfi JD. Validation of the Peritraumatic Distress Inventory's French translation. Can J Psychiatry. 2005;50 67-71.

39. Wittmann L, Moergeli H, Schnyder U. Low predictive power of peritraumatic dissociation for PTSD symptoms in accident survivors. J Trauma Stress. 2006;19:639-651.

40. Marmar CR, Weiss D, Metzler T. Peritraumatic dissociation and posttraumatic stress disorder. Trauma, Memory and Dissociation. Bremer D, Marmar C, editors. Washington DC: American Psychiatry Press; 1998:229-252.

41. Shalev AY, Peri T, Canetti L, Schreiber S. Predictors of PTSD in injured trauma survivors: a prospective study. Am J Psychiatry. 1996;153: 219-225.
Neuropsychiatric Disease and Treatment

\section{Publish your work in this journal}

Neuropsychiatric Disease and Treatment is an international, peerreviewed journal of clinical therapeutics and pharmacology focusing on concise rapid reporting of clinical or pre-clinical studies on a range of neuropsychiatric and neurological disorders. This journal is indexed on PubMed Central, the 'PsycINFO' database and CAS, and is the official

\section{Dovepress}

journal of The International Neuropsychiatric Association (INA). The manuscript management system is completely online and includes a very quick and fair peer-review system, which is all easy to use. Visit http://www.dovepress.com/testimonials.php to read real quotes from published authors. 